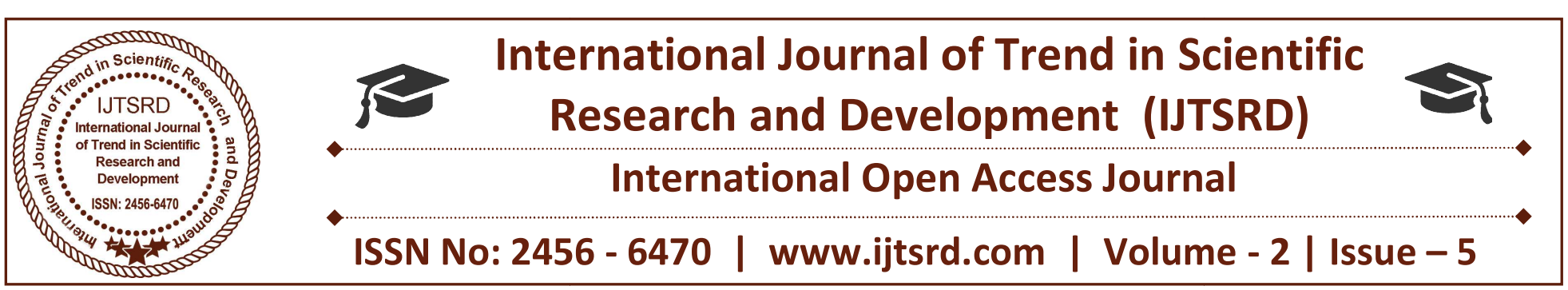

\title{
Road Accident Study on Some Areas in Yangon
}

\author{
Kyaing \\ Lecturer, Department of Civil Engineering, \\ Yangon Technological University, \\ Insein Road, Gyogone, Insein, Yangon, Myanmar
}

\begin{abstract}
Nowadays, road crashes become a growing worldwide problem and result in around 1 million deaths now occurs in developing countries. Huge economic losses are now being incurred annually in the ASEAN countries as a direct result of road crashes and the most recent research suggests annual losses across the region are now in excess of US dollar 14 billion per year (around 2.1\% of annual GDP of ASEAN region). In Myanmar, thousands of healthy lives are lost by road accidents comparing with other ASEAN countries. A research was conducted on a section of Pyay road with its high-accident locations to study and evaluate the cause of its frequent accidents. Initial study indicated that most of the accidents were attributed to human elements. This was included by the fact that a high percentage of accident was caused by the collision of moving vehicle and pedestrian. Identifying and removing hazardous spots to improve road safety will primarily requires well documented record on those roads with high-accident locations. These data base can inform to urban transport planner for road safety improvement.
\end{abstract}

Keywords: Road Accident, Pedestrian, Collision.

\section{INTRODUCTION}

Road accidents in a worldwide problem from which road crashes now-a-day claims the lives of about 1 million with 23 million injuries per year. Loss of properties amount to $\$ 500$ billion a year with an estimated $\$ 100$ billion borne by the Developing countries. It is alarming to note that the fatality rate is higher by (10-20) times in developing countries than that of the Developed Countries.

In ASEAN Countries alone 72,800 death and over 1.8 million injuries were recorded with many resulting in permanent disablement or serious injuries. Loss of properties is also in enormous proportion to about US\$ 11 billion.

WHO forecasts that health and disability from road accident will become increasingly more important health problems in all countries moving from 9th to $3 \mathrm{rd}$ position in the rank of the most important health problems worldwide by the year 2020. Whereas the more industrialized countries have in recent decades steadily and systematically reduced the accidents and severity of road crashes by implementing coordinated multi-sector remedial programs, the problem continue to grow in the developing regions.

This is particularly evident in Asia where the problem has now become very urgent and the number of death and injuries and loss of properties continue to grow rapidly. The increased of vehicular traffic under developed infrastructure and institution with further rapid motorization in recent years had all added to the growing problem of road accidents. High economic losses are now being sustained annually in the ASEAN countries as a direct result of road accidents.

Figure 1 shows trend of road accidents in Myanmar (2006-2017(Oct.)). It was on the rise with the consequent rise in both injuries and in death.

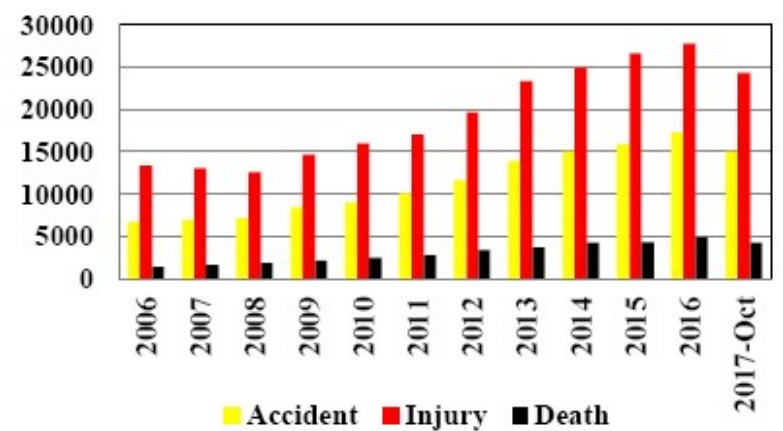

Fig. 1 Trend of Road Accidents in Myanmar (20062017(Oct)) 
Source: Road Transport Administration Department The population of urban area in Yangon is estimated to be 5.2 million (census, 2014) with the total number of vehicles at 691,456 in 2014 . Vehicle registrations of Yangon City are shown in Figure 2. As the number of motor vehicles and vehicle-miles of travel increase, the exposure of the population to traffic accident also increases.

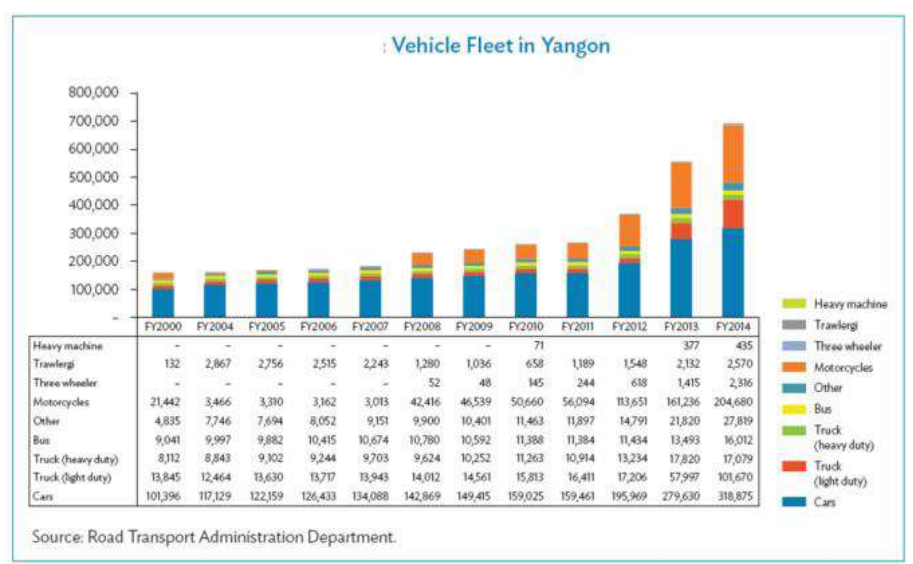

Fig. 2 Vehicle Registration in Yangon City Source: Road Transport Administration Department

Therefore, the purpose of this paper is to evaluate the cause of accident and explore measures for improving road safety of selected area in Yangon City.

The structure of this paper is organized as follows: related research works are presented in Section II. Section III briefly describes that how to collect the required data in study area. Traffic accidents of selected area are discussed in Section IV. Finally, conclusions and future work are presented in Section $\mathrm{V}$.

\section{RELATED RESEARCH WORKS}

Review of literature is important in any research work. Many researchers have carried out research work in the area of road accidents. Some of them have analyzed accident data in different ways. Some of them Identification of Black spot zone. Some of them have developed accident models for forecasting future accident trends. They have also proposed strategies for road safety. In the present paper literature review is carried out covering the different issues related to road accident and road safety.

K. Meshram and H. S. Goliya (2013) were presented an analysis of accidents on small portion NH-3 Indore to Dhamnod. The data for analysis is collected for the period of 2009 to September 2011. More accidents occurred in Manpur region by faulty road geometry.
The trend of accidents occurring in urban portion (Indore) is more than $35 \%$ to rate of total accidents in each year. This may due to high speeds and more vehicular traffic. In the present study area the frequency of fatal accidents are 2 in a week and 6 for minor accidents in a week. More number of accident observed in 6 p.m. to 8 p.m. duration because in that time more buses are travels between villages and city. One fatal and five casualties are occurring per km per year in the study area. The volume of the trucks passing through study corridor is increasing by year. At Rajendra Nagar from 2000 onwards the traffic is reduced due to the construction of by passes in that area.

Rakesh Mehar and Pradeep Kumar Agarwal (2013) were highlighted the deficiencies in the present state of the art and also presents some basic concepts so that systematic approach for formulation of a road safety improvement program in India can be developed. The study presents basic concepts to develop an accident record system, for ranking of safety hazardous locations, for identification of safety improvement measures and to determine priorities of safety measures. It is expected that this study will provide a systematic approach for development of road safety improvement program in India and thus pave the way for improving safety on Indian roads.

Yannis T. H. (2014) was presented A Review of The Effect of Traffic and Weather Characteristics on Road Safety. Despite the existence of generally mixed evidence on the effect of traffic parameters, a few patterns can be observed. For instance, traffic flow seems to have a nonlinear relationship with accident rates, even though some studies suggest linear relationship with accidents. Regarding weather effects, the effect of precipitation is quite consistent and leads generally to increased accident frequency but does not seem to have a consistent effect on severity. The impact of other weather parameters on safety, such as visibility, wind speed and temperature is not found straightforward so far. The increasing use of real-time data not only makes easier to identify the safety impact of traffic and weather characteristics, but most importantly makes possible the identification of their combined effect.

In this study, high-accident locations and causes of its frequent accidents for studied route are presented for record of traffic accident analysis. 


\section{III.STUDY AREA AND DATA COLLECTION}

\section{A. Section of Roadway Selected for Study}

Since a considerable extent of research work is involve with regard to road safety in Yangon and due to some constraints, this paper will focus the study on one of the most used main road in Yangon which extends into a highway up to Pyay. The section selected for study is a stretch of Pyay road between is terminal in the heart of Yangon city at Bogyoke Street and Tauk Kyant which covers of distance of 12 miles. The section selected for study area is shown in the following Figure 3.

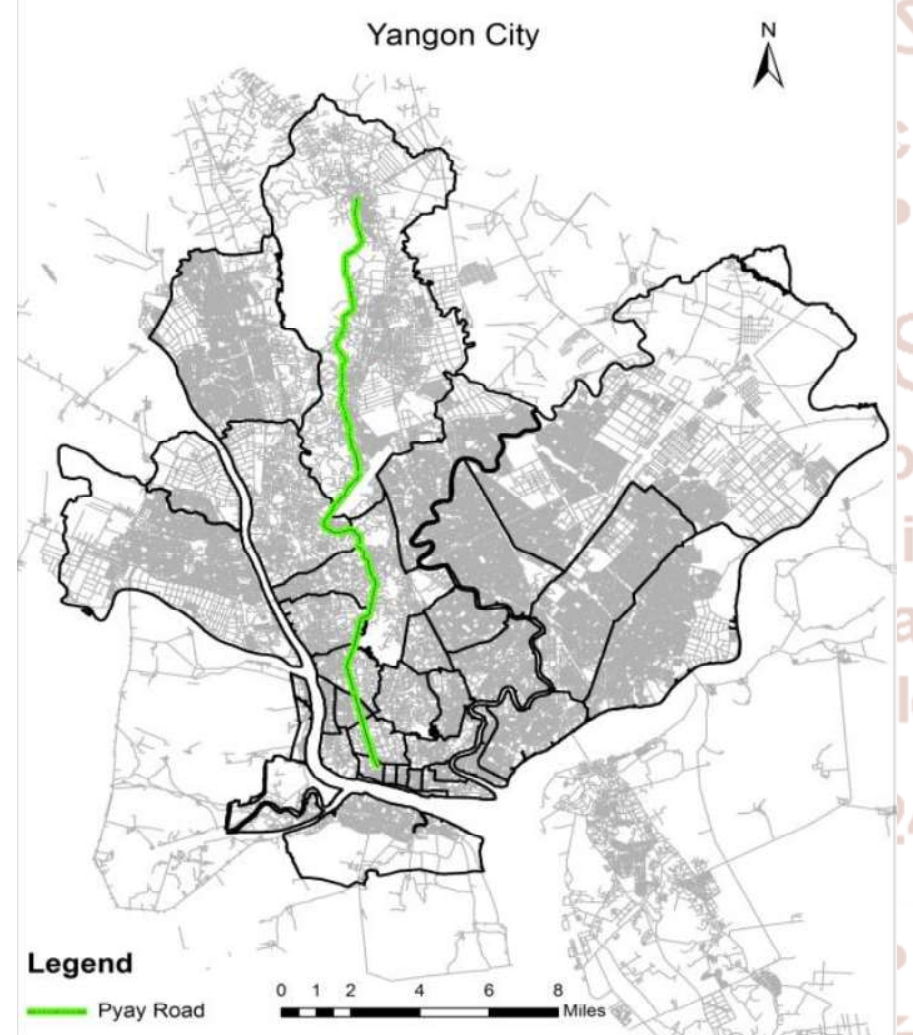

Fig.3 Selected Roadway for Studied Area

\section{B. Data Collection}

The presentation is based on research conducted on sections of some of the Pyay Road in Yangon. Data and Statistics on road accident and road safety measures of 2017 were collected from the traffic police department.

The types of accident are categorized into (4) main groups viz:

1. Collision on the road

2. Overturning of vehicle

3. Passenger falling off from moving vehicle

4. Other
Collision on the road listed as category (1) is again subdivided into (6) groups, viz:

A. Collision of moving vehicle with pedestrian

B. Collision between moving vehicles (may involve 2 or more vehicles)

C. Collision of moving vehicles with parked vehicles (may involve 2 or more vehicles)

D. Collision of moving vehicles with slow moving vehicle (1) non-motorized like bicycle, trishaw, cart; (2) motorized vehicles like trawlergi, trailer, semi-trailer

E. Collision of moving vehicles with stationary road side object such as lamp post, signs, billboards etc.

F. Collision with other objects like animal crossing road etc

Type of collision between motor vehicles, its highaccident locations and the causes of its frequent accidents are also collected for Pyay Road.

\section{IV.RESULTS AND DISCUSSIONS}

A. Traffic Accident in Yangon City

Figure 4 shows total accident, injury and death of Yangon City between 2011 and 2017. As seen in this Table, there is a steady rise in the number of traffic accident from 2011 to 2014 . However, small comfort can be taken from the fact that total accident, injury and fatalities per year decreased after 2014. This paper focuses only road accident data of 2017.

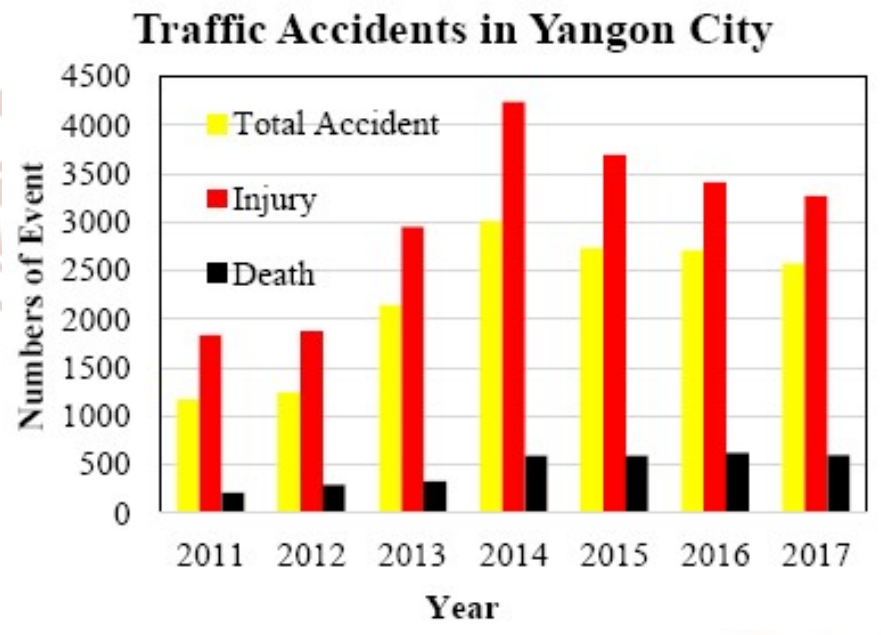

Fig. 4 Traffic Accident in Yangon City

B. Evaluation of Road Safety on the Studied Stretch of the Road

Traffic accidents are collected in Pyay Road of Yangon City. The following Figure 5 shows the 
number of events of traffic accident in studied route. From this Figure, it can be seen that injury is the highest and followed by fatality, and Property Damage Only (PDO) is the least. This spot map is shown in Figure 6.

\section{Number of Events}

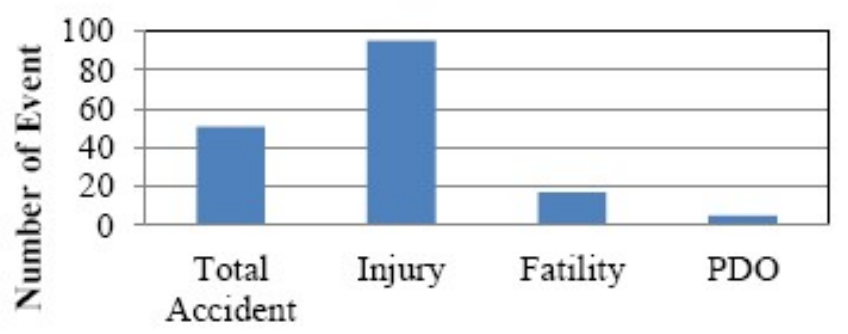

Type

Fig. 5 Number of Event for Traffic Accident

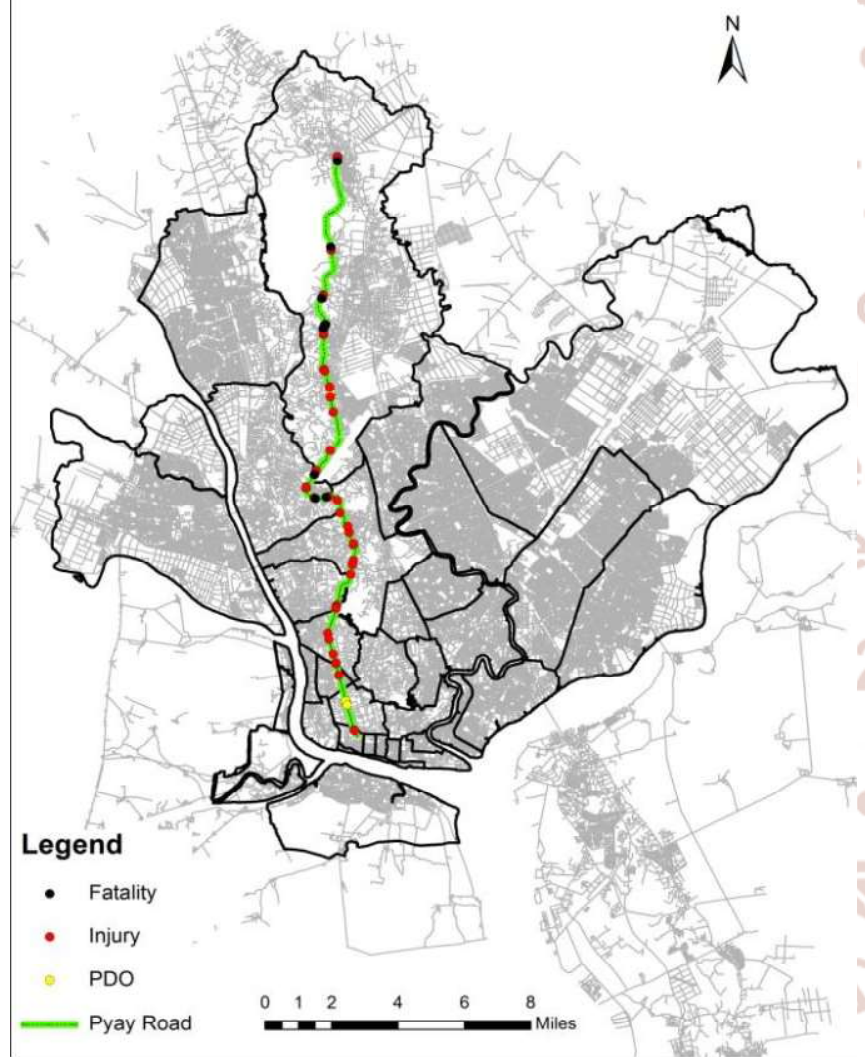

Fig. 6 Spot Map in Pyay Road
The study is based on the total number of accident which took place along the stretch of the road selected and are grouped into repetitive incidents w.r.t the vicinity of the same location. From the collected data, three repetitive incidents are two locations, two repetitive incidents are seven locations, and one case of traffic accident is 29 locations along the study route. And, it can be also seen that fatalities and injuries are the highest (fatality $=9$, Injuries $=32$ ) although accident is only one time in Mywemyuyae bus stop (Mingalardon Township). It was interesting to note that most accident occurred not only on it outskirts but also within the city limit. Even one of the accident locations (collision between ten vehiclesPDO) which is in front of entrance/exit gate of Yangon regional government office (Dagon Township) in close to the center of the city and under the close supervision of traffic control elements.

1. Numbers of Accident with Manner of Occurrence Numbers of accident with manner of occurrence of traffic accident in Pyay Road are shown in Figure 7.

\section{Number of Accident with Manner of} Occurrence

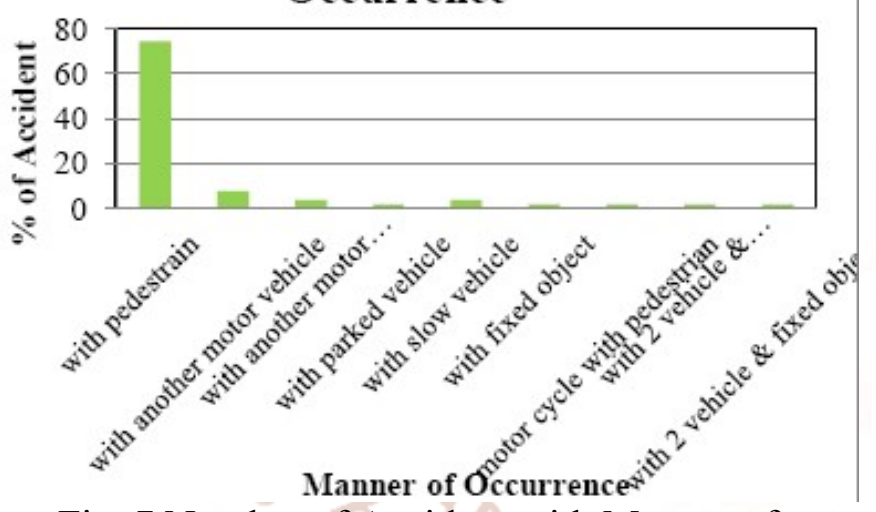

Fig. 7 Number of Accident with Manner of Occurrence

From information gathered, it was evident that a high proportion of accident is due to the collision of moving vehicle with pedestrian. $75 \%$ of accidents took place due to moving vehicle colliding with pedestrians. This indicates that human error plays a very prominent part in such incidents. Human error may be committed by either the driver of the vehicle or the pedestrian. Next on the high-accident list is the collision between vehicles which may involve two vehicles. This type of accident accounted for about $8 \%$ of the total accident. This again involves human elements. Disregard for road safety and road etiquette may contribute to the collision of vehicles in motion. Many a time this resulted in the loss of human lives as well as in huge loss of property.

\section{Number of Fatality}

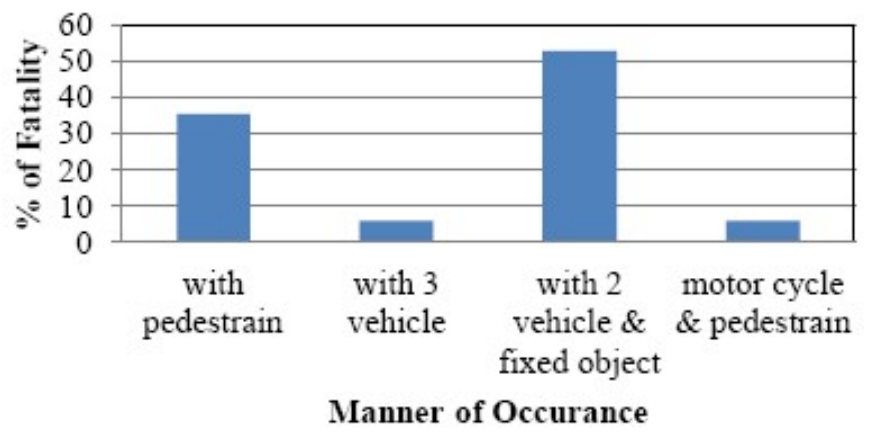

Fig. 8 Number of Fatality with Manner of Occurrence 
From Figure 8, it is found that fatality rate is the highest due to collision with two vehicle and fixed object.

2. Type of Collision between Motor Vehicles

The rear-end collision is the highest rate of collision between motor vehicles and followed by head on collision. Because, it is considered that rear end collision is due to over speed, unexpected stopping by the sudden change of traffic light and head-on collision is due to overtaking in opposite lane.

\section{Age of Drivers of Accidents in Yangon City} In 2017, the road accident occurred in Pyay Road in term of age groups is shown in Figure 9.

\section{$\%$ of Age of Drivers of Accidents}

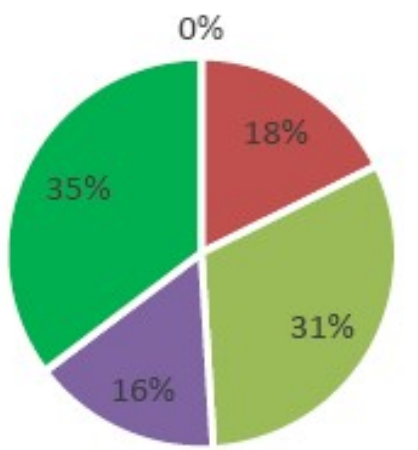

- Under 20

- 20-30

- 30-40

- Over 40

- Unspecified Group

Fig. 9 Age of Drivers of Accidents in Yangon City

This Figure point out that age group between 30 and 40 gives the highest accident except unspecified age group. From this factor, it can be inferred that most of the accident in Yangon caused by the negligence or recklessness or overconfidence. Some drivers did not take responsibility for their actions and ran away from accident places. This group represents unspecified age group in this study and it is found that the highest proportion in accident cases.

4. Road Accidents in Pyay Road by Time Period Road Accidents in Pyay Road are collected the accident occurring time in terms of hour, day, month and season.

\section{Road Accidents in Terms of Hour}

Road accidents need to be studied by hour-duration. This time period investigation help to know the highest rate on each day and control and road safety's time concern can be identified. This should be evaluated very well for the requirement of free from accidents. Twenty four hours can be divided into eight periods to be evaluated every three hours as shown in Figure 10.
This Figure shows that the highest rate of road accident occurred between 18:00 and 21:00 in year 2017. This factor points out that insufficient light on the road at night is the major source for accident. It is also found that most of the drivers drive high speed in this period.

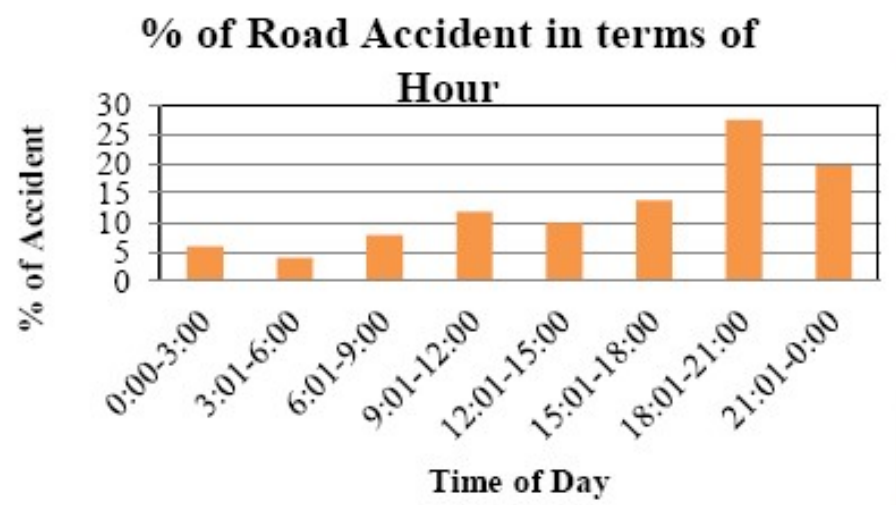

Fig. 10 Road Accidents in Pyay Road by Time Period

One would expect the majority of accident to take place during peak hour or the rush hour, when traffic is congested and many drivers are impatient. However the study shows that accidents during peak hours were not at all too high in the evening accident, during evening peak hour (17:00-19:00) is $14 \%$ and in the morning (8:00-10:00) it is even less during its peak hour at $10 \%$. There is a strong indication that drivers are more careful driving rush hours during which traffic police are in full force to keep the congested volume of traffic flowing smoothly. But the number of traffic accident in the evening period is higher than that of the morning which is not so surprising since considerable volume of vehicles are using the roads far into the night-there by often endangering the safety of pedestrians crossing roads

II. Road Accident in terms of Day, Month and Season The following Figure 11, 12 and 13 show the road accident in terms of day, month and season.

\section{$\%$ of Road Accident in terms of Day}

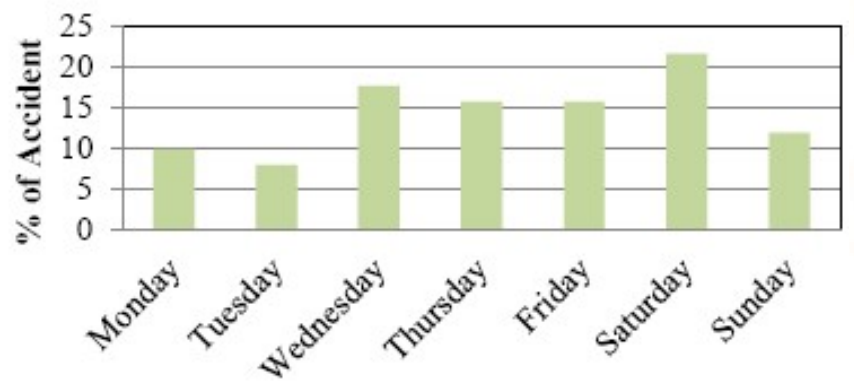

Days of Week

Fig. 11 Road Accident in terms of Day 
Figure 11 shows that the highest rate of accident occurs on Saturday. And, January and August become the black month for road accident as shown in Figure 12 .

Figure 13 shows the road accident in terms of season. In 2017, the highest rate of accident occurred in rainy season. This factor supports to ensure the fact that most of the road accident occurred in Pyay Road is due to the heavy rain.

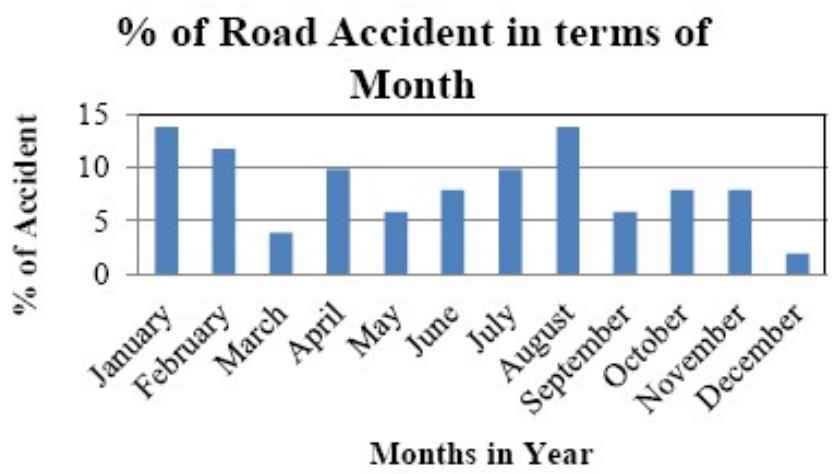

Fig. 12 Road Accidents in term of Month

\section{$\%$ of Road Accident in terms of Season}

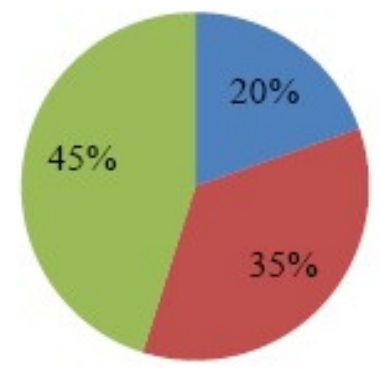

nummer - Winter nainy

Fig. 13 Road Accident in terms of Season

Therefore road lighting and traffic control devices such as regulatory devices, warning devices and guiding devices should be installed in accident locations of studied route.

\section{CONCLUSIONS}

Now-a-day the main roads in the city are in good condition, well maintained by the engineering department (Road and Bridge), Yangon City Development Committee (YCDC). Many traffic control devices for the road safety measures were installed; guard rails and islands were constructed; sign, signal and markings are properly maintained and road lightening is improved. Strong traffic police contingents are always on hand to keep the moving vehicles under control to keep the road safe for all road users.

With such road safety measures taken, accident still happened with loss of lives and damaged to properties. Statistics and research strongly indicate that human element plays a crucial role in making the road safe. And there may be parts of the road, which needs urgent improvement, from the engineering aspect to remove hazardous sections.

However, unless data pertaining to the physical condition of the road, its safety devices provided and the occurrence of accidents are fully documented and stored, and updated from time, hazardous spots cannot be accurately identified nor effectively improved.

Therefore the collection and maintain a record of accident, traffic and highway data is a perquisite for improving the safety of a road way. Such record should always be made available at all times.

Three years or five years data of city's urban area should be analyzed by using Geographic Information System (GIS). These data base can inform to urban transport planner for road safety improvement.

\section{ACKNOWLEDGEMENTS}

The author would like to express her appreciation to Traffic Police Department for data provided of this research.

\section{REFERENCES}

1. Athanasios Theofilatos and George, Yannis National "A review of the effect of traffic and weather characteristics on road safety", Accident Analysis and Prevention 72 (2014) 244-25, 2014.

2. K Meshram and H. S. Goliya "Accident Analysis on National Highway-3 between Indore to Dhamnod" International Journal of Application or Innovation in Engineering \& Management (IJAIEM) Volume 2, Issue 7, July 2013.

3. Rakeshmehar and Pradeepkumar agarwal "A systematic approach for formulation of a road safety improvement program in India", Procediasocial and Behavioral Sciences 104(2013) 10381047, 2013.

4. E. S. Park et al., "safety effects of wider edge lines on rural, two-lane highways", Accident Analysis and prevention vol-48,317-325, 2012. 
5. ADB/ASEAN Regional Road Safety Program, ADB RETA 6077, Project Summary, 2003.

6. ASEAN Road Safety Project-Country Workshops and Local Research, 2004.

7. "Fact Finding Mission for the Proposed ADB Assisted Road Safety Study", YCDC, 2004, Research Paper.

8. "Urban Environmental Planning for Myanmar", ADB RETA 5684-REG SETIS, 2004.

9. "Myanmar Police Force and the Traffic Police", Police Col. Myint Thein 2004, Research paper.
10. "The Role of Road Transport Administration Department in National Road Safety", RTAD 2004, Research Paper.

11. "Road Safety Planning and Safety Development in Yangon City, Myanmar", YCDC 2004, Research Paper.

12. "Road Safety Activities", TRESC 2004, Research Paper.

13. Roger P. Roess, Elena S. Prassas and William R. McShane. 2004,"Traffic Engineering" (Fourth Edition)

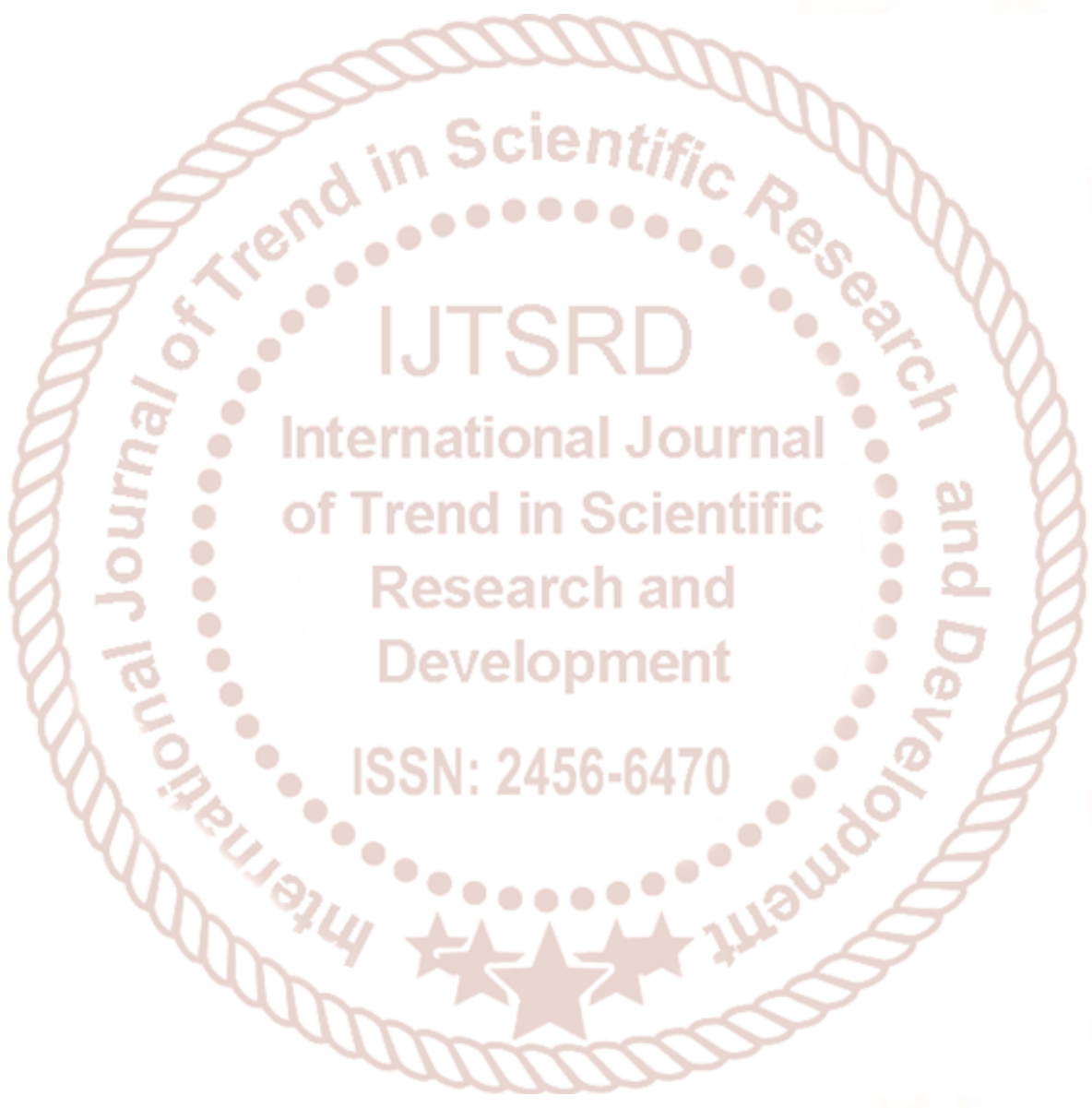

